\title{
Cannabinoid receptor 1 knockout alleviates hepatic steatosis by downregulating perilipin 2
}

\author{
Karuna Irungbam ${ }^{1} \cdot$ Yuri Churin ${ }^{1} \cdot$ Tomomitsu Matono $^{1} \cdot$ Jakob Weglage $^{1} \cdot$ Matthias Ocker $^{2,5} \cdot$ Dieter Glebe $^{3}$. \\ Martin Hardt ${ }^{4} \cdot$ Alica Koeppel $^{1} \cdot$ Martin Roderfeld $\mathbb{1}^{1} \cdot$ Elke Roeb $^{1}$
}

Received: 15 July 2019 / Revised: 30 August 2019 / Accepted: 8 September 2019 / Published online: 30 September 2019

(c) The Author(s) 2019. This article is published with open access

\begin{abstract}
The endocannabinoid (EC) system has been implicated in the pathogenesis of several metabolic diseases, including nonalcoholic fatty liver disease (NAFLD). With the current study we aimed to verify the modulatory effect of endocannabinoid receptor 1 (CB1)-signaling on perilipin 2 (PLIN2)-mediated lipophagy. Here, we demonstrate that a global knockout of the cannabinoid receptor 1 gene $\left(\mathrm{CB}^{-l-}\right)$ reduced the expression of the lipid droplet binding protein PLIN2 in the livers of $\mathrm{CB}^{-/-}$and hepatitis B surface protein (HBs)-transgenic mice, which spontaneously develop hepatic steatosis. In addition, the pharmacologic activation and antagonization of CB1 in cell culture also caused an induction or reduction of PLIN2, respectively. The decreased PLIN2 expression was associated with suppressed lipogenesis and triglyceride (TG) synthesis and enhanced autophagy as shown by increased colocalization of LC3B with lysosomal-associated membrane protein 1 (LAMP1) in $\mathrm{HBs} / \mathrm{CB} 1^{-1-}$ mice. The induction of autophagy was further supported by the increased expression of LAMP1 in $\mathrm{CB} 1^{-/-}$and HBs/CB1 ${ }^{-l-}$ mice. LAMP1 and PLIN2 were co-localized in HBs/CB1 $1^{-1-}$ indicating autophagy of cytoplasmic lipid droplets (LDs) i.e., lipophagy. Lipolysis of lipid droplets was additionally indicated by elevated expression of lysosomal acid lipase. In conclusion, these results suggest that loss of CB1 signaling leads to reduced PLIN2 abundance, which triggers lipophagy. Our new findings about the association between CB1 signaling and PLIN2 may stimulate translational studies analyzing new diagnostic and therapeutic options for NAFLD.
\end{abstract}

These authors contributed equally: Karuna Irungbam, Yuri Churin

These authors contributed equally: Martin Roderfeld, Elke Roeb

Supplementary information The online version of this article (https:// doi.org/10.1038/s41374-019-0327-5) contains supplementary material, which is available to authorized users.

Elke Roeb

elke.roeb@innere.med.uni-giessen.de

1 Department of Gastroenterology, Justus-Liebig-University, Giessen, Germany

2 Institute for Surgical Research, Philipps University of Marburg, Marburg, Germany

3 Institute of Medical Virology, National Reference Centre for Hepatitis B and D Viruses, Justus-Liebig-University, Giessen, Germany

4 Central Biotechnical Facility, Justus-Liebig-University, Giessen, Germany

5 Present address: Department of Gastroenterology CBF, Translational Medicine Oncology, Charité University Medicine Berlin and Bayer AG, Experimental Medicine Oncology, Berlin, Germany

\section{Introduction}

Hepatic steatosis and especially its progressive form nonalcoholic steatohepatitis (NASH) are major health problems and increasing causes for liver cirrhosis and hepatocellular cancer [1]. Disturbances in lipid metabolism play a critical role in the progression of nonalcoholic fatty liver disease (NAFLD) [2]. Though the regulating mechanisms of lipogenesis and lipolysis in NAFLD are discussed to a considerable extent in previous studies, the etiology of the disease remains elusive [1]. So far, there is no approved drug for the treatment of NAFL and NASH in patients. The treatment consists of lifestyle modification (e.g., sustainable weight reduction plans and physical training), which seems to improve the metabolic conditions linked to NAFLD [1, 3-5].

It has been reported that endocannabinoids (ECs) widely participate in central and peripheral lipid metabolism by activating $G$ protein-coupled cannabinoid receptors type 1 and type 2 (CB1 and CB2) [6]. ECs stimulate the appetite to increase energy intake, but also promote lipogenesis in peripheral tissues, such as the 
adipose tissue, liver, and skeletal muscles, thus leading to obesity and fatty liver disease [7]. The basal hepatic expression of $\mathrm{CBs}$ is faint, with low levels of $\mathrm{CB} 2$ receptors in Kupffer cells and of $\mathrm{CB} 1$ receptors in endothelial cells and hepatocytes [8]. ECs with diet-induced obesity have been associated with fatty liver, insulin resistance and other phenotypes [9]. CB1 receptors have been reported to play a role in the development of fatty liver in Zucker rats whereas the CB1 antagonist rimonabant reduced obesity-associated hepatic steatosis and inflammatory response [10]. CB1 knockout (CB1KO) mice are resistant to diet-induced obesity even though their total caloric intake is similar to that of wild type (WT) littermates, which became obese on the same diet [11]. Rimonabant was used for weight reduction in humans [12]. Moreover, the treatment of obese mice with rimonabant led to a transient reduction of food intake and a marked, but sustained reduction of body weight and adiposity of these animals [11]. Therefore, modulating the EC system in order to treat obesity and the associated metabolic disorders depicts a promising therapeutic concept [5]. However, the mechanism by which $\mathrm{CB} 1$ receptor deficiency or blockade increases energy expenditure has not yet been determined.

HBV associated steatosis has been reported from epidemiological and experimental studies [13]. Prevalence of histopathological steatosis in patients with chronic Hepatitis $\mathrm{B}$ is around $28 \%(12-76 \%)$ [14]. Transgenic mice overexpressing HBV surface proteins [15] developed hepatic steatosis [16]. Apart from steatosis, also other histopathological changes in the same transgenic model including inflammation, regenerative hyperplasia, ER stress, and associated unfolded protein response, which are based on hepatic accumulation of HBs, have been reported [17-19]. ER stress mediated response could be one of the reasons for hepatic steatosis [20].

Autophagy occurs as a response to starvation and energy depletion and is considered to be an alternative strategy for survival under shortage of energy supplies [21]. CB1 signaling influences autophagy, which might assist the cell in adjusting to different metabolic states. CB1 activity indeed alters the autophagic flux, and modulatory activity is exerted in a noncanonical mTOR and BECLIN1independent manner [22]. Furthermore, ECs play a role in inducing autophagy in various cancer cell lines [23]. Recently, the contribution of autophagy to cytoplasmic lipid droplets (cLD) degradation has been identified [21]. The link between autophagy and cLDs arose from the observation that lysosomal acid lipase (LAL) deficiency leads to an accumulation of cLDs in various organs [24]. Further, in order to deliver cellular LDs to the lysosomes, autophagosomes sequestrate these LDs and fuse with lysosomes, which then leads to degradation of the LDs [25].
A connection between chaperone-mediated autophagy (CMA) and macroautophagy in the clearance of hepatic LDs has been reported recently [26]. Perilipin 2 (PLIN2) deficiency enhances autophagy and depletes hepatic TG [26]. In addition, various genes encoding autophagic proteins have been manipulated to confirm the importance of autophagy/lipophagy in the regulation of hepatic triacylglycerol levels [27]. With the current study we demonstrate that the cannabinoid receptor CB1 affected the development of hepatic steatosis by regulating PLIN2 expression in HBs transgenic mice.

\section{Material and methods}

\section{Animals}

Mice with a global $\mathrm{CB} 1$ receptor knockout deletion were purchased from the European Mouse Mutant Archive. Generation and characteristics of transgenic lineage C.B6JTg (Alb1HBV)44Bri (HBVTg/c) has been described previously $[15,18]$. Hybrids of $\mathrm{CB}^{-1-}$ crossbred with HBVTg/six mice strain having inbred C57BL/6 genetic background were generated. At age of 12, 26, and 52 weeks ( $n=7-9)$ mice were weighed, anaesthetized by isofluran inhalation, and subsequently killed by cervical dislocation. The harvest was performed early in the morning in ad libitum fed state. Livers were weighed immediately after surgery and samples were preserved and stored at $-80^{\circ} \mathrm{C}$ until analysis.

Transgenic mice were maintained at the central animal laboratory of the Justus-Liebig-University Giessen under specified pathogen free conditions. This study was carried out in strict accordance as per the recommendations laid in the guide for the care and use of laboratory animals of the German law of animal welfare. The mice received humane care and all experiments were approved by the committee on the ethics of animal experiments of the Regierungspraesidium Giessen, Germany (approved no, GI 20/10 A5/ 2012 and 128/2014).

\section{Western blot}

Liver lysates were prepared in $1 \times$ Laemeli buffer and boil at $95{ }^{\circ} \mathrm{C}$ for $10 \mathrm{~min}$, and then briefly centrifuged for $5 \mathrm{~min}$. After SDS-PAGE, the gel was transferred to nitrocellulose membrane and immunoblotting procedures were followed as per the standard protocol. Proteins recognition was done by using specific antibodies against AMPK (Genetex, GTX50863-100), Phospho-AMPK (Genetex, GTX130429-25), LC3B (Novus, NB100-2220), p62 (Proteintech, 18420-1-AP), PLIN2 (Proteintech, 15294-1AP), PLIN4 (Merck, ABS526), PLIN3, PLIN5 (Progen: 
GP30S; GP31S), GAPDH (Proteintech,60004-1-Ig), and $\beta$ actin (Santa Cruz, sc47778). The proteins were visualized using peroxidase-conjugated secondary antibodies and chemiluminescent reagent, developed on X-ray developer machine (AGFA, CP1000) using high sensitivity film (Hypersensitive film, Amersham). Alternatively, proteins were visualized using alkaline phosphatase conjugated secondary antibodies and developed with soluble 5-bromo-4-chloro-3-indolyl phosphate and nitro blue tetrazolium.

\section{Histochemical analyses of mouse liver}

Immunohistochemistry (IHC) was performed using Impress Peroxidase/Alkaline Detection Reagents (Vector Laboratories) and antibodies specific for GLUT1 (Abcam, ab115730), LC3B (Proteintech, 18725-1-AP), /PLIN2 (Proteintech, 15294-1-AP), and LAL (Novus, NBPI54155SS). Double immunostaining was performed as described previously [28]. Color reaction was developed with the VECTOR VIP Peroxidase Substrate Kit, (Vector Laboratories) or HighDef ${ }^{\circledast}$ red IHC AP chromogen Enzo. Image quantification was performed using NIH ImageJ1.x software.

\section{Immunofluorescence microscopy}

Paraffin-embedded liver sections were used for performing the immunofluorescence staining. The sections were deparaffinized as per the standard protocol. Unmasking was done by boiling the sample in $1 \times$ citrate buffer in microwave oven for $10 \mathrm{~min}$. Blocking was done using 10\% BSA, $5 \%$ goat serum, and 5\% mouse IgG (MKB-2213, Vector Labs) in phosphate-buffered saline $(137 \mathrm{mM}$ sodium chloride, $3 \mathrm{mM}$ potassium chloride, $7 \mathrm{mM}$ disodium hydrogen phosphate, and $11 \mathrm{mM}$ dipotassium hydrogen phosphate, $\mathrm{pH}$ 7.4). Primary antibodies used for double staining; anti-rabbit LC3B, 1:100 (Proteintech, 18725-1AP), and anti-rabbit PLIN2, 1:200 (Proteintech, 15294-1AP), anti-mouse LAMP1, 1:100 (Genetex, GT25212), p62, 1:100 (Proteintech, 18420-1-AP). Fluorochrome-conjugated secondary antibodies, Alexa-488 or 546 (Invitrogen,) were used. Nucleus was stained with DAPI. Cover slips were mounted on using Fluoromount ${ }^{\mathrm{TM}}$ aqueous mounting medium (Sigma, F4680). All the images were acquired with Fluorescent microscope (Leica, Leitz, and DMR3) mounted with Nikon camera (Coolpix 5400) and prepared with Adobe Photoshop 7.0.

\section{Oil red 0 staining}

Oil red O staining was performed as described previously [29]. Staining was assessed by bright-field microscopy.

\section{Thin layer chromatography}

The lipid extraction from liver tissues was performed as described recently [30] with slight modifications. $20 \mathrm{mg}$ of frozen liver tissue were weighed and then homogenized with of hexane/2-propanol $3: 2(\mathrm{v} / \mathrm{v})$ to a final volume 50 times the volume of the tissue sample $(1 \mathrm{~g}$ in $50 \mathrm{ml}$ of solvent mixture) for $1 \mathrm{~h}$. After dispersion the whole mixture was centrifuged at $4{ }^{\circ} \mathrm{C}$ at $10,000 \times g$ for $10 \mathrm{~min}$. The supernatant was transferred to a new vial and dried under a nitrogen gas, resuspended in an appropriate volume of chloroform/methanol $2: 1(\mathrm{v} / \mathrm{v})$ and applied in equal amount onto pretreated, prewashed TLC plates. The standard (Nonpolar TLC standard, Bio trend Chemikalien, cat no.1130) and samples were applied onto the TLC plates and chromatographically separated with the solvent system containing hexane/diethylether/acetic acid (90:10:1(v/v/v) to the top of the plate. Detection and quantification was performed with charring method using N/10 sulfuric acids. Image was captured by gel doc analyzer (Biometra, Göttingen, Germany).

\section{Quantitative triglyceride estimation}

Quantitative estimation of triglycerides from the liver samples was performed as per the protocol provided in Abcam Triglycerides estimation kit (ab65336).

\section{Real-time PCR}

RNA isolation from the liver samples were performed using Direct-zol RNA extraction kit (Zymo research, Cat no. R2072). cDNA synthesis was done using iScript cDNA synthesis kit (BIO-RAD Cat no. 1708891) qRT-PCR was performed as described previously [31]. Primers were ordered from Microsynth (Switzerland). qPCR data were analyzed using $\Delta \Delta \mathrm{Ct}$ method [32]. Primers used: PLIN2 forward. 5-GACCTTGTGTCCTCCGCTTAT-3, reverse-5' CAACCGCAATTTGTGGCTC-3'; $\beta$-actin forward: $5^{\prime}$ CAG CTT CTT TGC AGC TCC TT-3', reverse: 5'-AGT CCT TCT GAC CCA TTC CC-3'.

\section{Cell culture and treatment with rimonabant}

The AML12 liver cell line (kind gift from Prof. Ralf Weiskirchen, Aachen) was cultured up to $90 \%$ confluency for all the assay in a 1:1 mixture of Dulbecco's modified Eagle's medium and Ham's F12 medium (Gibco, Grand Island, USA) with $0.005 \mathrm{mg} / \mathrm{ml}$ insulin, $0.005 \mathrm{mg} / \mathrm{ml}$ transferrin, $5 \mathrm{ng} / \mathrm{ml}$ selenium (ITS mixture, Gibco), $40 \mathrm{ng} / \mathrm{ml}$ dexamethasone (Sigma-Aldrich, St. Louis, MO), and supplemented with $10 \%$ fetal bovine serum (Gibco) at $37^{\circ} \mathrm{C}$ in a humidified atmosphere with $5 \% \mathrm{CO}_{2}$. 
For in vitro assay, rimonabant and methanandamide were dissolved in DMSO and applicated in presence of $2 \%$ FBS for $48 \mathrm{~h}$ in presence and absence of oleic acid (OA) as per the indicated doses for each assay. For induction of steatosis in vitro, cells were treated with OA (Sigma-Aldrich, St. Louis, MO) at a final concentration of $200 \mu \mathrm{M}$.

\section{Statistics}

All measurements were performed in technical triplicates. All results are expressed as means \pm standard error of the mean. Significant differences between four groups were determined by one-way ANOVA with Tukey's multiple comparisons test using to compare test groups. Differences between two groups were determined by Mann-Whitney's $U$ test. All statistical analyses were performed with GraphPad Prism software (v5.0; GraphPad Software Inc.,
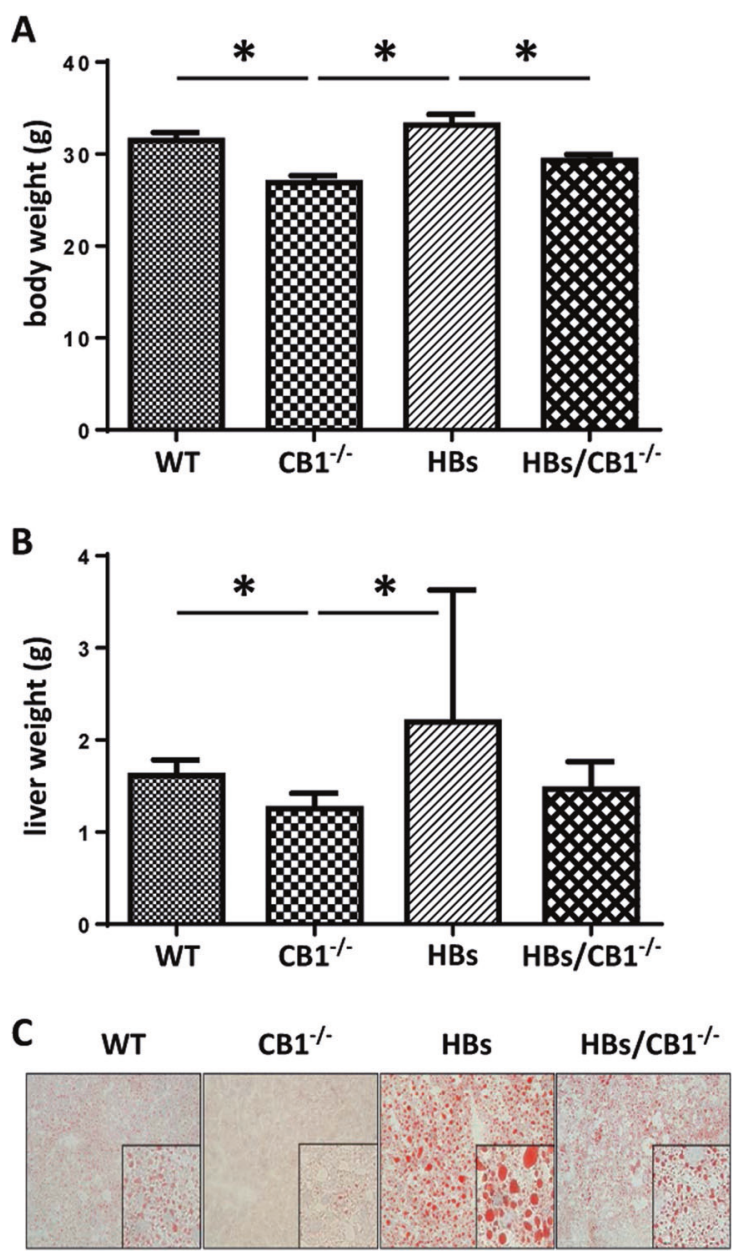

Fig. 1 CB1 receptor knockout decreased body weight and hepatic lipid accumulation in mice. a Bar diagram showed significant reduction of body weight in 52-week-old $\mathrm{CB} 1^{-1-}$ and $\mathrm{HBs} / \mathrm{CB} 1^{-1-}$ mice in comparison with WT and HBs. Depicted are means \pm SEM, $n=8-12$. b Liver weight was reduced in $\mathrm{CB}^{-1-}$-mice and enhanced in $\mathrm{HBs}$ transgenic mice. c Representative Oil red O staining of a 52-week-old
San Diego, CA) and $* p<0.05$, was considered statistically significant.

\section{Results}

\section{CB1 knockout (CB1K0) reduced hepatic triglycerides and lipid droplet accumulation in HBs transgenic mice}

Maintenance of body weight and energy homeostasis depends on the coordinated regulation of appetitive behavior and peripheral energy metabolism [33]. $\mathrm{CB}^{-/-}$and $\mathrm{HBs} / \mathrm{CB} 1^{-/-}$mice showed decreased body and liver weight compared with WT and HBs mice (Fig. 1a, b). As leanness has been associated with reduced steatosis, the effect of $\mathrm{CB} 1 \mathrm{KO}$ on hepatic fat was analyzed. Oil red staining

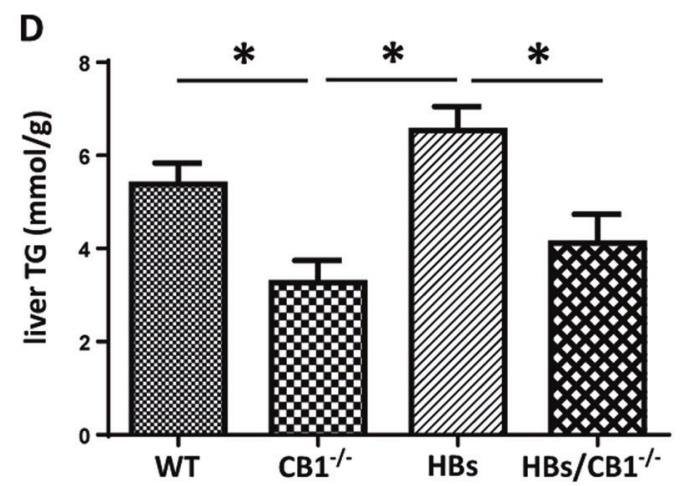

E

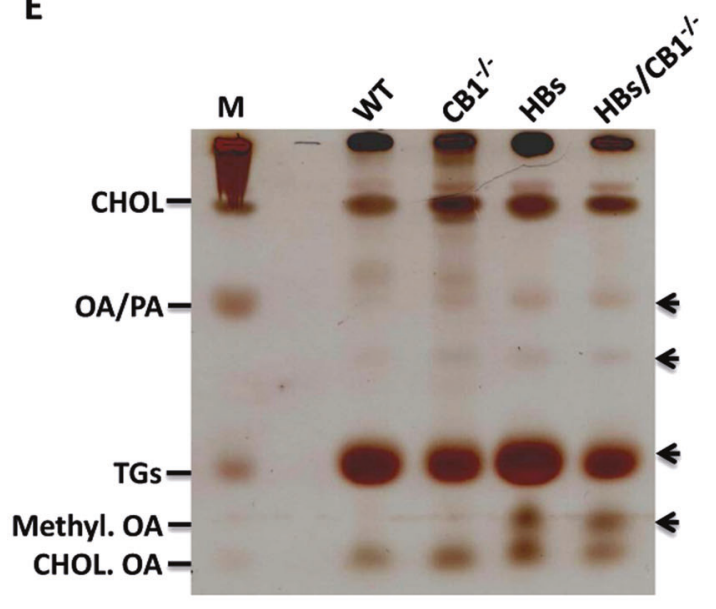

mouse liver. d Liver triglyceride analysis demonstrated significant reduction of TGs level in the liver of 52-week-old $\mathrm{CB}^{-/-}$and HBS/ $\mathrm{CB} 1^{-1-}$ mice. $n=7-9$. e Representative thin layer chromatography analysis demonstrated different total lipid profiles of 52-week-old mouse liver tissues. CHOL Cholesterol, OA/PA oleic acid/palmitic acid, TGs triglycerides 
visualized increased hepatic steatosis in HBs transgenic mice (Fig. 1c). The CB1KO diminished the size of hepatic $\mathrm{LDs}$ in $\mathrm{HBs} / \mathrm{CB}^{-/-}$mice. Quantification of liver TGs from liver samples of 52-week-old mice further demonstrated the reduction of $\mathrm{TGs}$ in $\mathrm{CB} 1^{-1-}$ and $\mathrm{HBs} / \mathrm{CB}^{-1-}$ compared with WT and HBs mice (Fig. 1d).

Thin layer chromatography analysis of the total hepatic lipid extracts visualized the increased amounts of TGs in HBs and decreased TGs in $\mathrm{CB} 1^{-/-}$and $\mathrm{HBs} / \mathrm{CB}^{-1-}$ compared with WT (Fig. 1e). Interestingly, free fatty acids (OA/PA) were increased in $\mathrm{CB}^{-l-}$, $\mathrm{HBs}$, and $\mathrm{HBs} / \mathrm{CB}^{-l-}$ mice, which might be an effect of increased degradation of TGs. Due to the increase in free fatty acids in HBs transgenic mice, methyl ester derivatives of OA in liver samples of HBs and $\mathrm{HBs} / \mathrm{CB}^{-1-}$ mice were also increased (Fig. 1d). The cholesterol level remained unchanged. Taken together, these findings support the idea that the $\mathrm{CB} 1 \mathrm{KO}$ led to the reduction of the size of hepatic LDs and TGs. In order to complement the features of NAFLD, we analyzed IL- $1 \beta$ and TNF- $\alpha$ as well as $\alpha \mathrm{SMA}$ and desmin to assess $\mathrm{CB} 1^{-1-}$-induced changes with regard to inflammation and fibrosis. Interestingly, inflammation and fibrosis were not significantly altered in $\mathrm{HBs} / \mathrm{CB}^{-1-}$ in comparison with HBs mice (Supplementary Figs. 1 and 2). Nevertheless, $\alpha$ SMA expression was increased in HBs transgenic mice in comparison with WT and $\mathrm{CB} 1^{-1-}$ mice and at least normalized by trend in $\mathrm{HBs} /$
$\mathrm{CB}^{-l-}$ (Supplementary Fig. 2A). Serum aminotransferases ALT and AST were not regulated between HBs and HBs/ $\mathrm{CB}^{-1-}$ mice (not shown).

\section{CB1 knockout reduced PLIN2 expression}

The interesting changes in the shape and size of hepatic LDs in $\mathrm{HBs} / \mathrm{CB} 1^{-1-}$ mice raised the question, whether the mechanism of LD formation might be affected by the CB1KO. Perilipins are the major CLD-associated proteins which are involved in intracellular LD formation. The protein family consists of five members [34]. Among them, PLIN2 represents a constitutively and ubiquitously expressed protein that is used as a marker of LDs [26]. We observed lower expression levels of PLIN2 in the livers of $\mathrm{CB} 1^{-1-}$ and $\mathrm{HBs} / \mathrm{CB} 1^{-1-}$ in comparison with WT and HBs mice (Fig. 2a-c). PLIN2 mRNA level was decreased in $\mathrm{CB}^{-l-}$ and $\mathrm{HBs} / \mathrm{CB}^{-l-}$ compared with WT and HBs mice, respectively (Fig. 2a). This reduction of PLIN2 correlated with the reduction of TGs (Fig. 1). Western blot analysis and densitometric analysis demonstrated similar results on protein level. Immunostaining visualized the decreased PLIN2 expression in hepatocytes of $\mathrm{HBs} / \mathrm{CB}^{-l-}$ compared with HBs mice (Fig. 3c). The hepatic expression of other PLIN family members like PLIN3 and PLIN5 had been described before in the
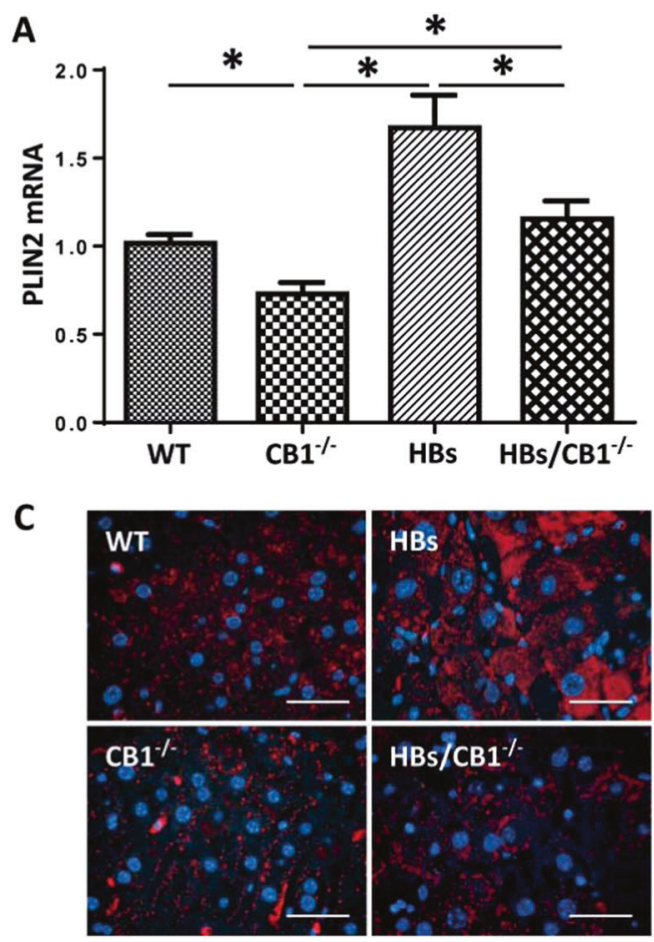

Fig. 2 CB1 knockout reduced hepatic PLIN2 in HBs transgenic mice. a Quantitative real-time PCR analysis of PLIN2 revealed reduced PLIN2 mRNA in $\mathrm{CB}^{-1-}$ and $\mathrm{HBS} / \mathrm{CB}^{-/-}$-mice. Data were normalized to $\beta$-actin as reference gene and shown as relative expression $(\Delta \Delta \mathrm{Ct})$. b Western blot analysis of total protein lysates from the liver

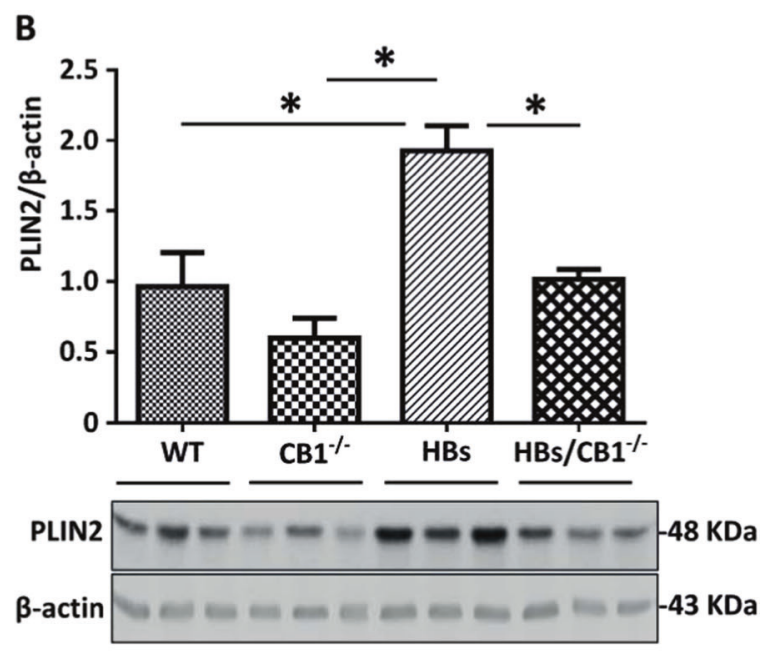

of 52-week-old mice demonstrates reduced PLIN2 protein levels in $\mathrm{HBs} / \mathrm{CB}^{-l-}$ mice. c Immunofluorescence analysis of paraffinembedded liver sections from 52-week-old mice was performed using specific anti-PLIN2 antibody (red). Nuclei were stained with DAPI (blue). Original magnification $\times 1000$, bar $40 \mu \mathrm{m}$ 
A

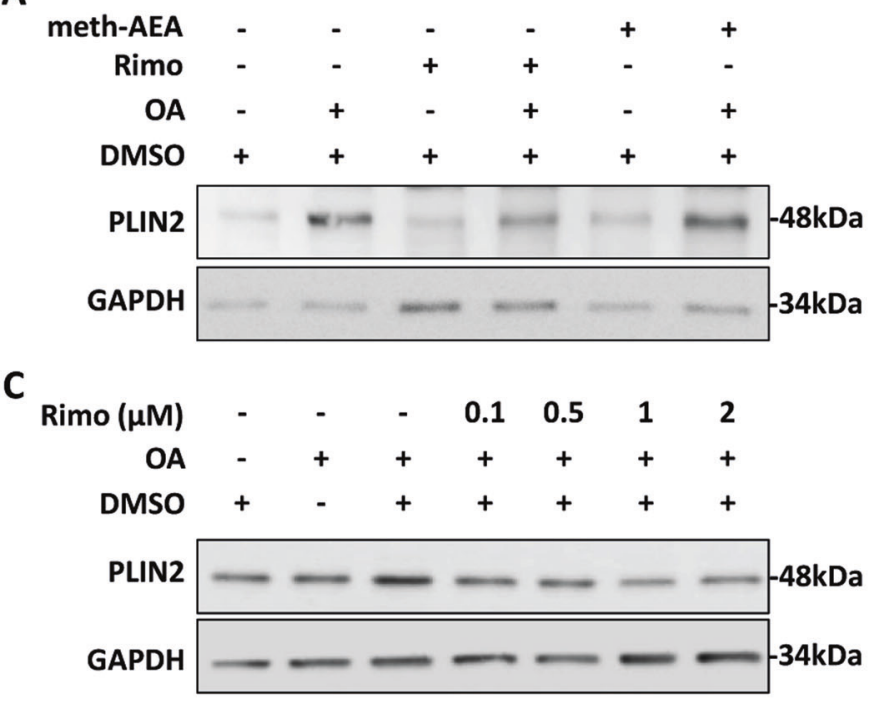

B

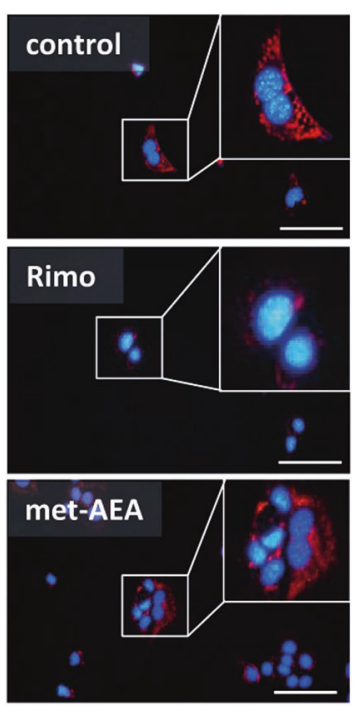

Fig. 3 Pharmacologic antagonization of CB1 reduced PLIN2 expression in cell culture a AML12 cells were treated with rimonabant (rimo) or methanadamide (meth-AEA) at $1 \mu \mathrm{M}$ final concentration for $48 \mathrm{~h}$ in the absence or presence of oleic acid $(200 \mu \mathrm{M})$. Western blot analysis demonstrated enhanced PLIN2 expression with meth-AEA and reduced PLIN2 expression with rimo-treatment. Equal protein loading was confirmed using anti-GAPDH antibody. A representative Western Blot is shown. b Immunofluorescence analysis of PLIN2 (red) in

context of lipid metabolism [35] and was therefore also analyzed by western blot (Supplementary Fig. 2). PLIN3 protein expression was upregulated in $\mathrm{HBs} / \mathrm{CB}^{-1-}$ while PLIN4 was downregulated in $\mathrm{HBs}$ and $\mathrm{HBs} / \mathrm{CB} 1^{-1-}$ similarly. PLIN5 protein expression was decreased in the liver of $\mathrm{HBs}$ mice in comparison with $\mathrm{HBs} / \mathrm{CB}^{-1-}$ (Supplementary Fig. 3).

Analyses of PLIN2 expression in AML12 cells treated with the specific CB1 inhibitor rimonabant (Rimo) and agonist methanadamide (meth-AEA) were performed to prove the regulation of PLIN2 by CB1 mechanistically. Immunoblotting and immunofluorescence analysis were performed showing that inhibiting CB1 caused a decrease in PLIN2 expression in comparison with both vehicle control and meth-AEA (Fig. 3a, b). PLIN2 expression was also dose-dependently downregulated by Rimo in AML12 cells after OA treatment when compared with vehicle control (DMSO with OA) (Fig. 3c). Taken together, in vivo and in vitro experiments demonstrated hepatocellular reduction of PLIN2 expression by both CB1 receptor knockout and antagonization, respectively.

\section{CB1 knockout elevated autophagy in the liver of HBs transgenic mice}

Autophagy is a response to starvation or energy depletion, and it is considered to be an alternative strategy for survival
AML12 cells treated with rimonabant or meth-AEA. Nuclei were stained with DAPI (blue). Representative stainings are shown. Original magnification $\times 400$, bar $100 \mu \mathrm{m}$. $\mathbf{c}$ Dose dependent decrease in PLIN2 expression in AML12 cells treated with rimonabant at different doses $(0.1,0.5,1$, and $2 \mu \mathrm{M})$, respectively. in the presence of oleic acid $(200 \mu \mathrm{M})$. Cell lysates were analyzed by western blot using specific anti-PLIN2 antibodies. Equal protein loading was confirmed using an anti-GAPDH antibody

under such circumstances [21]. Therefore, we investigated whether there might be an enhancement of autophagy due to CB1KO. The expression levels of the proteins LC3B and p62 which are classical markers for autophagy were analyzed by western blotting [36]. LC3B immunostaining was significantly increased in $\mathrm{HBs} / \mathrm{CB}^{-1-}$ indicating enhanced autophagosome-formation (Fig. 4a, b). Western blotting demonstrated that LC3B protein expression was reduced by trend in $\mathrm{HBs} / \mathrm{CB}^{-/-}$as compared with $\mathrm{HBs}$ transgenic mice (Fig. 4c and Supplementary Fig. 4A) possibly suggesting an autophagic flux. A temporal western blot analysis of total liver protein from $\mathrm{HBs}$ and $\mathrm{HBs} / \mathrm{CB}^{-1-}$ mice showed that LC3B II levels were increased in $\mathrm{HBs} / \mathrm{CB}^{-1-}$ compared with $\mathrm{HBs}$ at 12 and 26 weeks (Supplementary Fig. 4B). Interestingly, LC3B II levels were reduced after 52 weeks (Supplementary Fig. 4B and Fig. 4c). This decrease in elder animals might be due to temporally manifested stronger nutrient stress mediated by combined effects of CB1KO and HBs expression in hepatocytes [22]. Furthermore, LC3B II protein expression was also induced by rimonabant treatment in cell culture (data not shown). Hepatic p62 protein expression was decreased in $\mathrm{HBs} /$ $\mathrm{CB}^{-1-}$ mice as compared with HBs mice (Fig. 4c). The staining of lysosomal-associated membrane protein 1 (LAMP1) revealed an enhanced expression of LAMP1 in $\mathrm{CB} 1^{-1-}$ and $\mathrm{HBs} / \mathrm{CB}^{-1-}$ in comparison with WT and $\mathrm{HBs}$ mice (Fig. 4d). 
Fig. 4 CB1 knockout elevated autophagy in the liver of HBs transgenic mice.

a Representative

immunohistochemical analysis of paraffin-embedded liver sections from 52-week-old mice was performed using anti-LC3B antibody. Original image magnification $\times 1000$, bar $40 \mu \mathrm{m}$. b Quantification of LC3B puncta assessed with ImageJ software and expressed as \% of LC3B staining/field. c Western blot analysis of lysates from 52-week-old mice was performed using specific antiLC3B and anti-p62 antibodies. d Representative

immunofluorescence analysis of paraffin-embedded liver sections of 52-week-old mice was performed using specific antiLAMP1 antibodies (red). Nuclei were stained with DAPI (blue). Magnification $\times 1000$, bar $40 \mu \mathrm{m}$
A

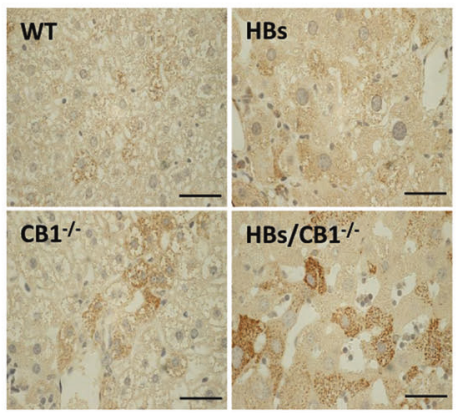

C

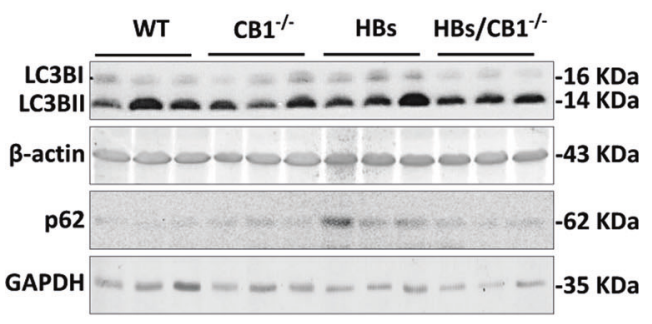

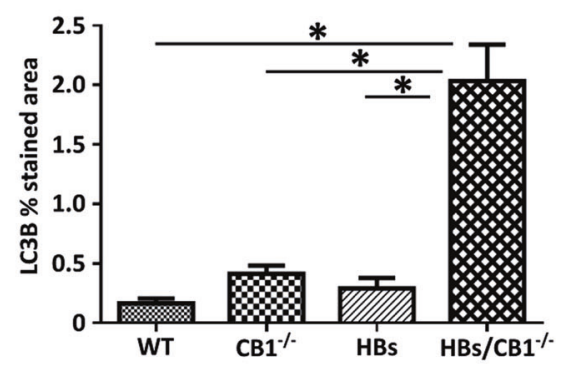

D
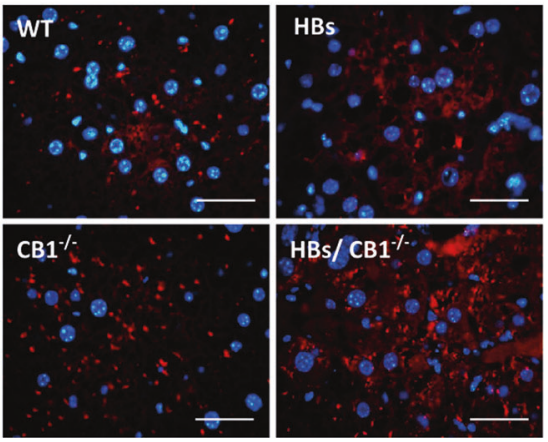

Double immunofluorescence staining using anti-LC3B and anti-LAMP1 antibodies showed enhanced colocalization in $\mathrm{HBs} / \mathrm{CB}^{-1-}$ mice as compared with $\mathrm{HBs}$ mice (Fig. 5a). Moreover, double immunofluorescent staining using anti-p62 and anti-LAMP1 antibodies showed a partial colocalization of p62 with LAMP1 in $\mathrm{HBs} / \mathrm{CB} 1^{-1-}$ (Fig. 5b). Interestingly, p62 was also localized within the nuclear inclusions (Fig. 5b) and therefore protected from degradation by autophagy.

LAL is an acidic hydrolytic enzyme, which is responsible for lipid digestion. Its expression was assessed as an indicator of autophagy-mediated digestion of LDs [25]. Immunostaining of LAL revealed an increased accumulation of LAL protein in hepatocytes of $\mathrm{HBs}$ and $\mathrm{CB} 1^{-1-}$ mice compared with WT mice (Fig. 5c). The strongest accumulation of LAL protein was observed in hepatocytes of $\mathrm{HBs} / \mathrm{CB} 1^{-1-}$ mice. To further confirm specific autophagy of lipids, immunohistochemical analyses of LAMP1 with PLIN2 were performed. We observed a stronger colocalization of LAMP1 and PLIN2 in $\mathrm{HBs} / \mathrm{CB} 1^{-1-}$ than in WT or HBs (Fig. 5d). Taken together, the lack of CB1 signaling enhanced the autophagic flux leading to an autophagy-mediated lipolysis of TGs in hepatocytes of HBs transgenic mice.

\section{CB1KO suppressed hepatic lipogenesis}

Disturbance of hepatic glucose uptake has been described as an indicator of metabolic stress [37] and lipogenesis. Immunohistochemical analysis revealed an increased localization of glucose transporter GLUT1 and GLUT2 in plasma membranes of hepatocytes in $\mathrm{HBs} / \mathrm{CB}^{-/-}$compared with HBs (Supplementary Fig. 4A, B), suggesting a change in hepatic energy metabolism. Overall GLUT1 protein expression and mRNA level remained unchanged (data not shown). It has been reported that CB1KO leads to increased hepatic AMPK activation [9]. Western blot analysis of phospho-AMPK just demonstrated a tendential activation of AMPK in CB1KO in comparison with WT while this effect was abolished in $\mathrm{HBs} / \mathrm{CB} 1^{-/-}$ (Supplementary Fig. 5B). As the activation of AMPK may inhibit various anabolic pathways and stimulates catabolic pathways to restore the energy homoestasis [38], we explored the effect of CB1KO on lipogenesis. Fatty acid synthase and Acetyl-CoA-Carboxylase were decreased in $\mathrm{CB}^{-1-}$ in comparison with $\mathrm{HBs}$ and WT (Fig. 6a). The transcriptional expression level of peroxisome proliferator-activated receptor gamma (PPAR $\gamma$ ) was reduced in $\mathrm{CB} 1 \mathrm{KO}$ and $\mathrm{HBs} / \mathrm{CB} 1^{--}$in comparison with WT and HBs as shown in Supplementary Fig. 5D. Monoacylglycerol O-acyltransferase 1 (MGAT1) was significantly increased in HBs in comparison with WT whilst it was downregulated in $\mathrm{HBs} / \mathrm{CB} 1^{-1-}$ in comparison with HBs (Fig. 6a, b). Similarly, the transcriptional level of MGAT1 was also upregulated in HBs in comparison with $\mathrm{CB}^{-1-}$ (Fig. 6c). IHC visualized the decrease in DGAT1 protein expression in $\mathrm{HBs} / \mathrm{CB}^{-/-}$in comparison with HBs (Fig. 6d). In summary, CB1KO suppressed hepatic lipogenesis and TG synthesis in HBs/ $\mathrm{CB}^{-1-}$ mice. 

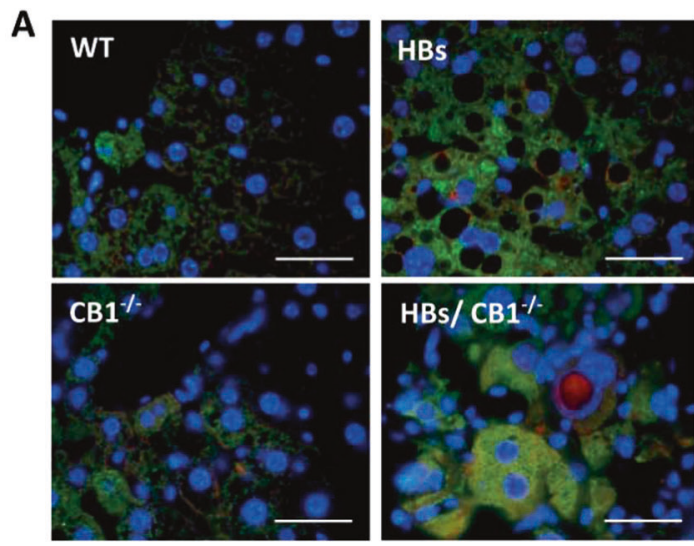

C
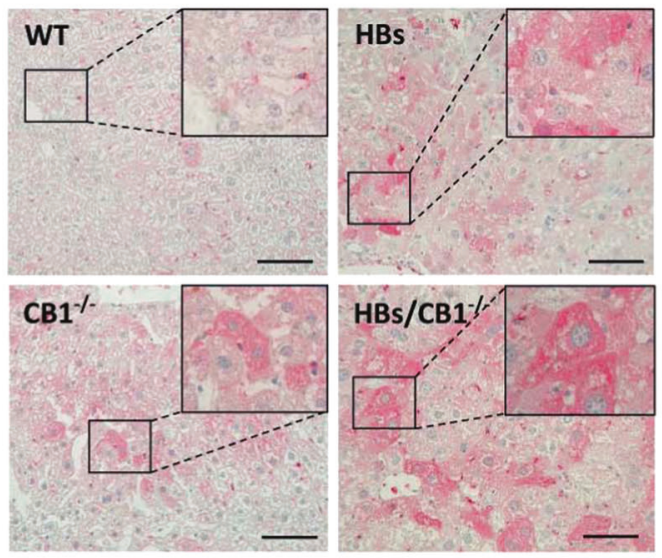

Fig. 5 a Double immunofluorescence analysis of paraffin-embedded liver sections of 52-week-old mice was performed using specific antiLC3B (green) and LAMP1 (red) antibodies. Nuclei were stained with DAPI (blue). Colocalization of these two proteins appears in yellow. Magnification $\times 1000$ Scale bar $40 \mu \mathrm{m}$. b Representative double immunofluorescence analysis of paraffin-embedded liver sections from 52-week-old mice was performed using anti-p62 (green) and antiLAMP1 (red). Arrowheads indicate colocalization of these proteins

\section{Discussion}

In the current study, we investigated the impact of CB1 receptor knockout on fat accumulation in the livers of HBs transgenic mice which spontaneously develop hepatic steatosis [16]. EC signaling is known to regulate appetite, energy balance, and metabolic processes through both central and peripheral pathways [33]. ECs mediate their effects on energy and lipid metabolism by activating CB1 or CB2 receptors. Several studies using genetic deletion mutants or pharmacological antagonization of CB1 receptor have demonstrated anorectic effects that improved obesity as well as hepatic steatosis and metabolic disturbances [39]. It has been shown that $\mathrm{CB} 1^{-/-}$ protects from steatosis in alcoholic liver injury, which provoked the suggestion that $\mathrm{CB} 1$ receptor activation aggravates SREBP-1c-mediated steatosis after ethanol intake [40]. Those data confirm the current findings. Our data also demonstrate the reduction of body weight, liver
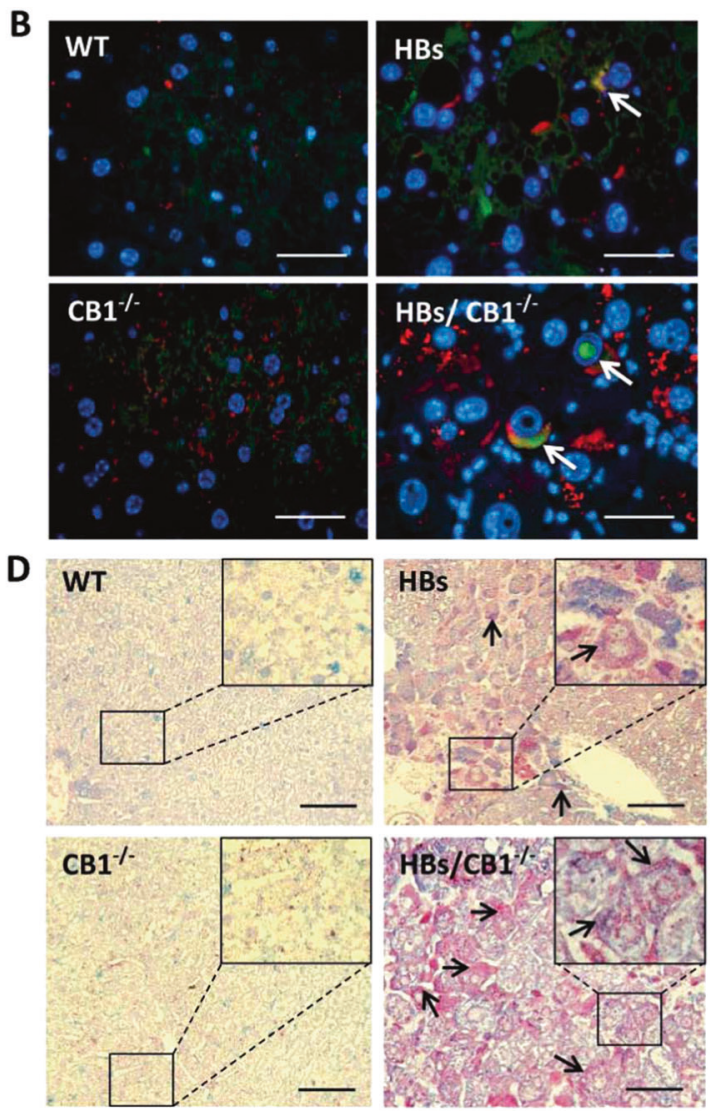

shown in yellow color and p62 accumulation in nuclear inclusion. Original image magnification $\times 1000$, bars $40 \mu \mathrm{m}$. c Representative immunohistochemical analysis of paraffin-embedded liver sections from 52-week-old mice was performed using specific anti-LAL (lysosomal acid lipase) antibody. Original magnification $\times 200$ and $\times 1000$, bar $100 \mu \mathrm{m}$. d Representative immunohistochemical analysis of PLIN2 (blue) and LAMP1 (red). Arrows show costained areas (purple color). Original magnification $\times 200$ and $\times 1000$, bar $100 \mu \mathrm{m}$

weight, and liver TGs in murine steatosis (Fig. 1a-e), thus confirming the previous findings.

The effect of $\mathrm{CB} 1 \mathrm{KO}$ on the reduction of LDassociated PLIN2 expression has not been described previously. Whole body knockout of PLIN2 decreased the hepatic triglyceride level and protected against dietinduced obesity, and liver steatosis [41]. Protection against fatty liver in normal adipogenesis was documented in mice lacking adipose differentiation-related protein, another name of PLIN2 [42]. The reduction of PLIN2 expression by antisense oligonucleotide treatment led to decreased hepatic lipid accumulation [43]. Furthermore, a PLIN2 liver-specific ablation alleviates dietinduced hepatic steatosis and inflammation [44]. Herein, a phosphatidylethanolamine $\mathrm{N}$-methyltransferase-mediated mechanism that involves compensatory changes in proteins involved in phospholipid remodeling, inflammation, and ER stress has been suggested to alleviate diet-induced NASH. All these studies support an important role for 

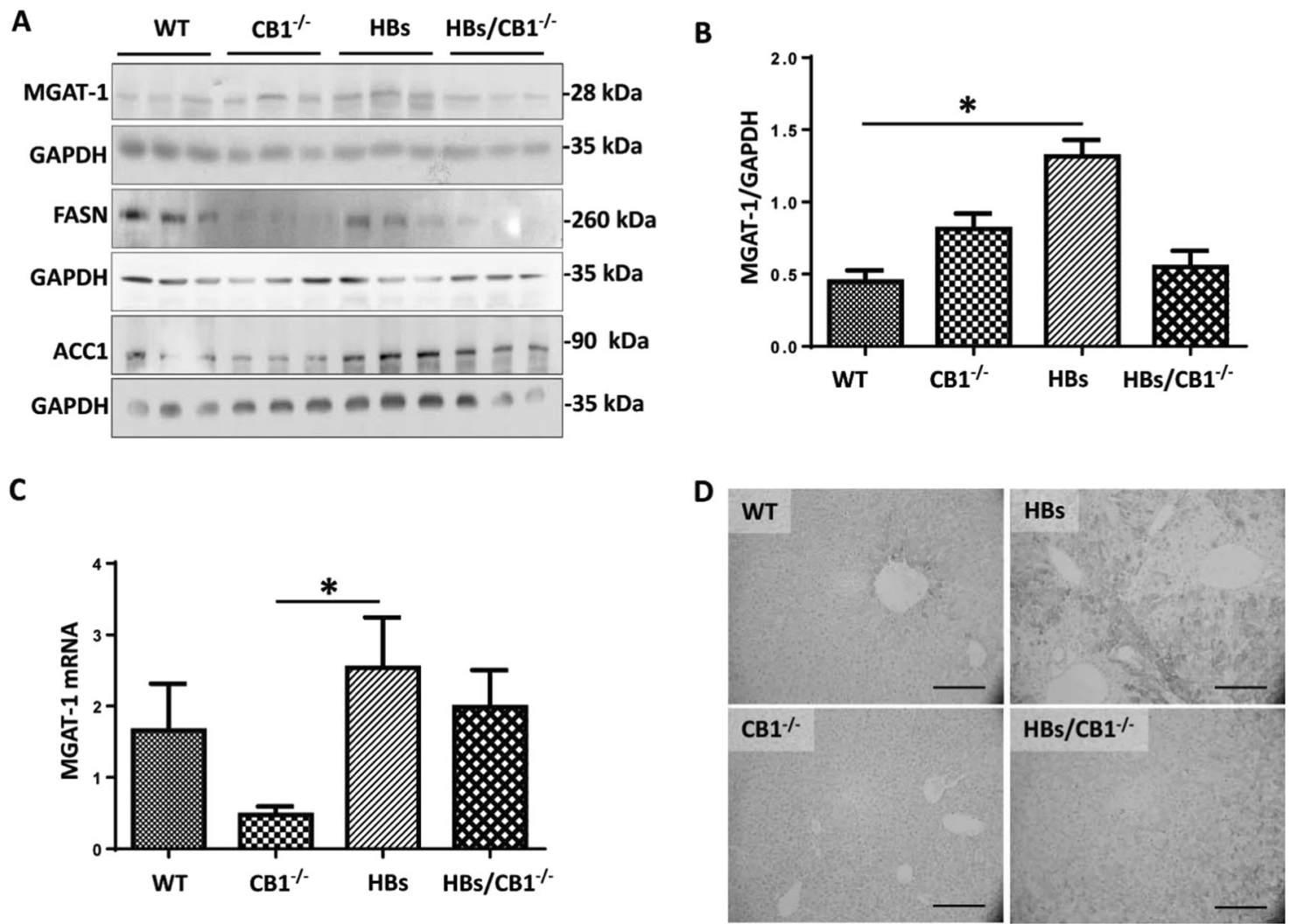

Fig. 6 CB1 knockout induced suppression of lipogenesis in HBs transgenic mice. a Western blot analysis of liver lysates of 52-week-old mice was performed using specific anti-MGAT1, anti-FASN, and anti-ACC1 antibodies. Equal protein loading was controlled by anti-GAPDH and anti- $\beta$-actin antibodies, respectively. b Bar graph representing normalized MGAT1 protein expression to GAPDH. Statistic, one-way ANOVA, Kruskal-Wallis test $(P=0.004)$, Dunnet's multiple comparison test were performed. c Quantitative real-time PCR (qRT-PCR) analysis of MGAT1 transcript was performed. The amount of RNA in the different samples is normalized to $\beta$-actin as reference gene and shown as relative expression $(\Delta \Delta \mathrm{Ct})$. Statistical analysis was performed in GraphPad, One-way ANOVA (Kruskal-Wallis test, $P=0.0053$ ). Dunn's multiple comparison test was used to compare among different group. d Representative immunohistochemistry of paraffin section using specific DGAT1 antibody. Magnification, $\times 200$ bar $200 \mu \mathrm{m}$

PLIN2 as a target for NASH therapy. Here we have demonstrated that the hepatic PLIN2 expression was reduced in the livers of $\mathrm{CB}^{-l-}$ and $\mathrm{HBs} / \mathrm{CB}^{-I-}$ mice (Fig. 2a-c). In order to show that the hepatic changes of Perilipin 2 expression were at least in part a direct result of abolishing CB1 in liver, and not secondary effects of the reduced food intake and body weight phenotype associated with the loss of CB1 in CNS, pharmacologic CB1 antagonization was performed to demonstrate the effect in cell culture. Very interestingly, loss of hepatic PLIN2 was further shown to be associated with minor increases in PLIN3 and PLIN5 levels in $\mathrm{CB} 1^{-/-}$and HBs/ $\mathrm{CB} 1^{-1-}$ mice (Supplementary Fig. 3 A, B). The increase in PLIN3 might possibly be a compensatory mechanism regulating LD accumulation in the absence of PLIN2 [45]. PLIN5 is most highly expressed in oxidative tissues such as skeletal muscle, and considered to promote fat oxidation [46]. Therefore, the minor changes in PLIN5 might suggest an increased oxidative degradation of TGs in CB1KO mice.
Previous studies reported that cannabinoids and activation of cell surface cannabinoid receptors could bind directly and indirectly to PPARs [47]. PLIN2 can be regulated through PPAR $\alpha$ and PPAR $\gamma$ [46]. In the current study PPAR $\gamma$ was downregulated in $\mathrm{CB} 1 \mathrm{KO}$ and $\mathrm{HBs} / \mathrm{CB} 1$ mice suggesting to be one of the mechanisms for $\mathrm{CB} 1 \mathrm{KO}$ mediated regulation of PLIN2 expression (Supplementary Fig. 5D). Moreover, the downregulation of PLIN2 by CB1KO further leads to suppression of lipogenesis and TGs synthesis (Fig. 6) as described previously [48]. Similarly, the reduced expression of PLIN2 in AML12 following rimonabant treatment strengthens the hypothesis of the direct association between CB1 signaling and PLIN2 in hepatocytes (Fig. 3a-c). Hence, altering the expression level of PLIN2 could be a mechanism of CB1-mediated regulation of hepatic lipid metabolism. Furthermore, the depletion of PLIN2 resulted in reduced food intake in response to HFD feeding [42]. Food intake was also lower in $\mathrm{CB} 1^{-1-}$ [49]. Since the global CB1KO was used in our study, we could not rule out the possibility that the cannabinoid receptor regulated food intake also affected 
PLIN2 expression. However, the cell culture experiments clearly demonstrated a reduction of PLIN2 expression by CB1 antagonization and an induction of PLIN2 expression by the CB1 activator meth-AEA. Therefore, it is likely that CB1KO regulates PLIN2 expression which further supports our hypothesis that PLIN2 was regulated by the CB1KO in murine liver. It was previously shown that LDs can be selectively sequestered in autophagosomes and delivered to lysosomes for degradation by LALs - a process known as "lipophagy" [21]. PLIN2, being the major LDs associated protein, protects and stabilizes LDs, provides a "shielding effect" and modulates lipase's accessibility to TG [50]. Removal of the LD surface proteins, PLIN2 by CMA (chaperon mediated autophagy) represents the preliminary step that helps to open up the lipid components of LDs core for degradation by lipophagy or cytosolic lipase. Moreover, it has been previously reported that downregulation of PLIN2 stimulates the breakdown of TGs via autophagy [26]. Therefore, downregulation of PLIN2 could be considered as a pivotal step promoting autophagic lipolysis of LDs.

AMPK (AMP-activated protein kinase) is a sensor of energy status that responds to the increase of AMP or ADP cellular concentrations to maintain cellular energy homeostasis [51]. Although we could demonstrate a tendential increase in phosphor-AMPK in the livers of $\mathrm{CB}^{-/-}$, AMPK was not activated in $\mathrm{HBs} / \mathrm{CB}^{-1-}$ mice (Supplementary Fig. 5C). Further, it has been reported that stimulation of AMPK is associated with enhancement of GLUT1mediated glucose transport [52]. Our study demonstrated increased hepatic membrane localization of GLUT1 (supplementary Fig. 5A). Changes in GLUT1 conformation and cellular localization seem to be part of an adaptive host response to maintain adequate cellular nutrition and energy levels [53]. The production of endogenous HBV surface proteins in the hepatocytes of $\mathrm{HBs}$ mice might induce additional cellular stress, which could explain the higher surge of energy as shown by increased GLUT1 localization on plasma membrane. Interestingly, GLUT1 expression could be regulated by hypoxia [54]. In the livers of $\mathrm{HBs} /$ $\mathrm{CB}^{-1-}$ mice GLUT1 was not regulated on mRNA and protein levels (data not shown) that excluded any effect of hypoxia on GLUT1 in our model. Recent studies demonstrated that $\mathrm{CB} 1 \mathrm{KO}$ can modulate the autophagic flux in a noncanonical mTOR and BECLIN1-independent manner [22]. Autophagic flux implies autophagic degradation activity [36]. So far, a reliable biological markers used for identifying autophagic flux are the LC3B II turnover or SQSTM1/p62 degradation. Proofing this, however, imposes a challenge in an experimental set up to access the magnitude of autophagic flux especially in a steady state condition [55]. Therefore, we demonstrated increased autophagosomes formation as depicted by increased LC3B puncta and increased colocalization of LC3B and LAMP1. Moreover, immunoblotting showed decreased LC3B II protein levels in $\mathrm{HBs} / \mathrm{CB}^{-l-}$ which could be an effect of enhanced autophagic flux progression (Fig. $4 \mathrm{a}-\mathrm{d}$ ). The p62 protein expression level decreased in the liver of $\mathrm{HBs} / \mathrm{CB} 1^{-l-}$ compared with HBs mice (Fig. 4c). However, we demonstrated partial colocalization of p62 with LAMP1 that indicated autophagic degradation of p62 marked proteins and also p62 accumulation in nuclear inclusions (Fig. 5b). The transgenic model of HBV surface antigens exhibited nuclear inclusions in hepatocytes [56]. The fraction of nuclear inclusion localized p62 might be protected from degradation thus providing a possible explanation for similar expression levels of p62 in the livers of WT and $\mathrm{HBs} / \mathrm{CB} 1^{-/-}$mice (Fig. 5b). In addition, the expression of LAMP1 has been reported as a marker to assess autophagic flux [57]. Hepatic LAMP1 protein expression was increased in our model (Fig. 5a) further indicating autophagic flux mediated by CB1KO. Furthermore, expression of acidic lipases, LAL (lysosomal-associated lipase), is assessed as an indicator of autophagy-mediated digestion of LDs [21]. LAL was upregulated in the livers of $\mathrm{HBs} / \mathrm{CB} 1^{-/-}$mice that indicated enhanced lipolysis (Fig. 5c). In addition, the partial localization of LAMP1 and PLIN2 suggests the induction of lipophagy (Fig. 5d). Taken together, we demonstrated several markers that suggest enhanced autophagic flux and autophagic mediated lipolysis in HBs/ $\mathrm{CB}^{-/-}$. Finally, LD-associated lipases (ATGL) were not regulated by $\mathrm{CB}^{-1-}$ (not shown) but we cannot exclude the possibility that any other lipolytic mechanisms could play a role in the effects observed.

In conclusion, we demonstrated that the $\mathrm{CB} 1$ receptor knockout in vivo and pharmacologic antagonization of CB1 in cell culture decreased PLIN2 expression, which might be an essential step in lipid breakdown (schematically summarized in Supplementary Fig. 6). Thus, pharmacologic modulation of the CB1-PLIN2 axis might represent a novel therapeutic approach for the treatment of steatosis.

Acknowledgements We thank Heike Muller and Annette Tschuschner for excellent technical assistance. This work was supported by grants from DAAD (\#91606935 to KI), von-Behring-Roentgen Foundation (\#58-0005 to ER and \#60-0002 to MR), and University Medical Center Giessen and Marburg (UKGM) (\#21_2013 GI to ER and \#7_2014 GI to MR).

\section{Compliance with ethical standards}

Conflict of interest The authors declare that they have no conflict of interest.

Publisher's note Springer Nature remains neutral with regard to jurisdictional claims in published maps and institutional affiliations. 
Open Access This article is licensed under a Creative Commons Attribution 4.0 International License, which permits use, sharing, adaptation, distribution and reproduction in any medium or format, as long as you give appropriate credit to the original author(s) and the source, provide a link to the Creative Commons license, and indicate if changes were made. The images or other third party material in this article are included in the article's Creative Commons license, unless indicated otherwise in a credit line to the material. If material is not included in the article's Creative Commons license and your intended use is not permitted by statutory regulation or exceeds the permitted use, you will need to obtain permission directly from the copyright holder. To view a copy of this license, visit http://creativecommons. org/licenses/by/4.0/.

\section{References}

1. Younossi ZM, Loomba R, Rinella ME, Bugianesi E, Marchesini G, Neuschwander-Tetri BA, et al. Current and future therapeutic regimens for nonalcoholic fatty liver disease and nonalcoholic steatohepatitis. Hepatology. 2018;68:361-71.

2. Saponaro C, Gaggini M, Carli F, Gastaldelli A. The subtle balance between lipolysis and lipogenesis: a critical point in metabolic homeostasis. Nutrients. 2015;7:9453-74.

3. Alwahsh SM, Gebhardt R. Dietary fructose as a risk factor for non-alcoholic fatty liver disease (NAFLD). Arch Toxicol. 2017;91:1545-63.

4. Roeb E, Geier A. Nichtalkoholische steatohepatitis (NASH)aktuelle Behandlungsempfehlungen und zukünftige Entwicklungen. Z fur Gastroenterol. 2019;57:508-17.

5. Mallat A, Teixeira-Clerc F, Deveaux V, Manin S, Lotersztajn S. The endocannabinoid system as a key mediator during liver diseases: New insights and therapeutic openings. $\mathrm{Br} \mathrm{J}$ Pharmacol. 2011;163:1432-40.

6. Caraceni P, Domenicali M, Giannone F, Bernardi M. The role of the endocannabinoid system in liver diseases. Best Pract Res Clin Endocrinol Metab. 2009;23:65-77.

7. Liu LY, Alexa K, Cortes M, Schatzman-Bone S, Kim AJ, Mukhopadhyay B, et al. Cannabinoid receptor signaling regulates liver development and metabolism. Development. 2016;143:609-22.

8. Bátkai S, Osei-Hyiaman D, Pan H, El-Assal O, Rajesh M, Mukhopadhyay $\mathrm{P}$, et al. Cannabinoid-2 receptor mediates protection against hepatic ischemia/reperfusion injury. FASEB J. 2007;21:1788-800.

9. Kunos G, Osei-Hyiaman D, Liu J, Godlewski G, Bátkai S. Endocannabinoids and the control of energy homeostasis. J. Biol. Chem. 2008;283:33021-5.

10. Gary-Bobo M, Elachouri G, Gallas JF, Janiak P, Marini P, Ravinet-Trillou C, et al. Rimonabant reduces obesity-associated hepatic steatosis and features of metabolic syndrome in obese Zucker fa/fa rats. Hepatology. 2007;46:122-9.

11. Ravinet Trillou C, Arnone M, Delgorge C, Gonalons N, Keane P, Maffrand J-P, et al. Anti-obesity effect of SR141716, a CB1 receptor antagonist, in diet-induced obese mice. Am J Physiol Regul Integr Comp Physiol. 2003;284:345-53.

12. Christensen R, Kristensen PK, Bartels EM, Bliddal H, Astrup A. Efficacy and safety of the weight-loss drug rimonabant: a metaanalysis of randomised trials. Lancet. 2007;370:1706-13.

13. Misra B, Singh S. Nonalcoholic fatty liver disease and hepatitis B virus infection. Hep B Annu. 2012;9:86.

14. Shi J-P, Fan J-G, Wang H, Wu R, Gao X-Q, Zhang L. et al. Prevalence and risk factors of hepatic steatosis and its impact on liver injury in Chinese patients with chronic hepatitis B infection. J Gastroenterol Hepatol. 2008;23:1419-25.

15. Chisari FV, Filippi P, Buras J, McLachlan A, Popper H, Pinkert $\mathrm{CA}$, et al. Structural and pathological effects of synthesis of hepatitis B virus large envelope polypeptide in transgenic mice. Proc Natl Acad Sci USA. 1987;84:6909-13.

16. Chung Y-L, Wu M-L. The role of promyelocytic leukemia protein in steatosis-associated hepatic tumors related to chronic hepatitis B virus infection. Transl Oncol. 2018;11:743-54.

17. Chisari FV, Klopchin K, Moriyama T, Pasquinelli C, Dunsford HA, Sell S, et al. Molecular pathogenesis of hepatocellular carcinoma in hepatitis B virus transgenic mice. Cell. 1989;59:1145-56.

18. Churin Y, Roderfeld M, Stiefel J, Würger T, Schröder D, Matono $\mathrm{T}$, et al. Pathological impact of hepatitis B virus surface proteins on the liver is associated with the host genetic background. PLoS ONE. 2014;9:e90608.

19. Montalbano R, Honrath B, Wissniowski TT, Elxnat M, Roth S, Ocker M, et al. Exogenous hepatitis B virus envelope proteins induce endoplasmic reticulum stress: involvement of cannabinoid axis in liver cancer cells. Oncotarget. 2016;7:20312-23.

20. Baiceanu A, Mesdom P, Lagouge M, Foufelle F. Endoplasmic reticulum proteostasis in hepatic steatosis. Nat Rev Endocrinol. 2016;12:710-22.

21. Singh R, Kaushik S, Wang Y, Xiang Y, Novak I, Komatsu M, et al. Autophagy regulates lipid metabolism. Nature. 2009;458:1131-5.

22. Hiebel C, Kromm T, Stark M, Behl C. Cannabinoid receptor 1 modulates the autophagic flux independent of mTOR- and BECLIN1-complex. J. Neurochem. 2014;131:484-97.

23. Dando I, Donadelli M, Costanzo C, Dalla Pozza E, D'Alessandro A, Zolla L, et al. Cannabinoids inhibit energetic metabolism and induce AMPK-dependent autophagy in pancreatic cancer cells. Cell Death Dis. 2013;4:664-664.

24. Tuohetahuntila M, Molenaar MR, Spee B, Brouwers JF, Wubbolts $\mathrm{R}$, Houweling $\mathrm{M}$, et al. Lysosome-mediated degradation of a distinct pool of lipid droplets during hepatic stellate cell activation. J. Biol. Chem. 2017;292:12436-48.

25. Singh P, Han EH, Endrizzi JA, O’Brien RM, Chi Y-I. Crystal structures reveal a new and novel FoxO1 binding site within the human glucose-6-phosphatase catalytic subunit 1 gene promoter. J Struct Biol. 2017;198:54-64.

26. Tsai T-H, Chen E, Li L, Saha P, Lee H-J, Huang L-S, et al. The constitutive lipid droplet protein PLIN2 regulates autophagy in liver. Autophagy. 2017;13:1130-44.

27. Settembre C, Fraldi A, Medina DL, Ballabio A. Signals from the lysosome: a control centre for cellular clearance and energy metabolism. Nat Rev Mol Cell Biol. 2013;14:283-96.

28. Graumann F, Churin Y, Tschuschner A, Reifenberg K, Glebe D, Roderfeld M, et al. Genomic methylation inhibits expression of hepatitis B virus envelope protein in transgenic mice: a noninfectious mouse model to study silencing of HBV surface antigen genes. PLoS ONE. 2015;10:e0146099.

29. Levene AP, Kudo H, Armstrong MJ, Thursz MR, Gedroyc WM, Anstee QM, et al. Quantifying hepatic steatosis-more than meets the eye. Histopathology. 2012;60:971-81.

30. Laggai S, Simon Y, Ranssweiler T, Kiemer AK, Kessler SM. Rapid chromatographic method to decipher distinct alterations in lipid classes in NAFLD/NASH. World J Hepatol. 2013;5:558.

31. Roderfeld M, Rath T, Voswinckel R, Dierkes C, Dietrich H, Zahner D, et al. Bone marrow transplantation demonstrates medullar origin of CD34+ fibrocytes and ameliorates hepatic fibrosis in Abcb4 ${ }^{-1-}$ mice. Hepatology. 2010;51:267-76.

32. Livak KJ, Schmittgen TD. Analysis of relative gene expression data using real-time quantitative PCR and the 2(-Delta Delta C(T)) Method. Methods. 2001;25:402-8.

33. Cota D. CB1 receptors: emerging evidence for central and peripheral mechanisms that regulate energy balance, metabolism, and cardiovascular health. Diabetes Metab Res Rev. 2007;23:507-17.

34. Sztalryd C, Brasaemle DL. The perilipin family of lipid droplet proteins: gatekeepers of intracellular lipolysis. Biochim Biophys Acta Mol Cell Biol Lipids. 2017;1862:1221-32. 
35. Langhi C, Marquart TJ, Allen RM, Baldán A. Perilipin-5 is regulated by statins and controls triglyceride contents in the hepatocyte. J Hepatol. 2014;61:358-65.

36. Klionsky DJ, Abdelmohsen K, Abe A, Abedin MJ, Abeliovich H, Acevedo Arozena A, et al. Guidelines for the use and interpretation of assays for monitoring autophagy (3rd edition). Autophagy. 2016;12:1-222.

37. Hayashi T, Hirshman MF, Fujii N, Habinowski SA, Witters LA, Goodyear LJ. Metabolic stress and altered glucose transport: activation of AMP-activated protein kinase as a unifying coupling mechanism. Diabetes. 2000;49:527-31.

38. Mihaylova MM, Shaw RJ. The AMPK signalling pathway coordinates cell growth, autophagy and metabolism. Nat Cell Biol. 2011;13:1016-23.

39. Shi D, zhan $X, Y u X$, Jia M, Zhang Y, Yao J, et al. Inhibiting CB1 receptors improves lipogenesis in an in vitro non-alcoholic fatty liver disease model. Lipids Health Dis. 2014;13:173.

40. Trebicka J, Racz I, Siegmund SV, Cara E, Granzow M, Schierwagen $\mathrm{R}$, et al. Role of cannabinoid receptors in alcoholic hepatic injury: steatosis and fibrogenesis are increased in CB2 receptor-deficient mice and decreased in $\mathrm{CB} 1$ receptor knockouts. Liver Int Off J Int Assoc Study Liver. 2011;31:860-70.

41. Chang BH-J, Li L, Paul A, Taniguchi S, Nannegari V, Heird WC, et al. Protection against fatty liver but normal adipogenesis in mice lacking adipose differentiation-related protein. Mol Cell Biol. 2006;26:1063-76.

42. McManaman JL, Bales ES, Orlicky DJ, Jackman M, MacLean PS, Cain $\mathrm{S}$, et al. Perilipin-2-null mice are protected against dietinduced obesity, adipose inflammation, and fatty liver disease. $\mathrm{J}$ Lipid Res. 2013;54:1346-59.

43. Imai Y, Varela GM, Jackson MB, Graham MJ, Crooke RM, Ahima RS. Reduction of hepatosteatosis and lipid levels by an adipose differentiation-related protein antisense oligonucleotide. Gastroenterology. 2007;132:1947-54.

44. Najt CP, Senthivinayagam S, Aljazi MB, Fader KA, Olenic SD, Brock JRL, et al. Liver-specific loss of Perilipin 2 alleviates dietinduced hepatic steatosis, inflammation, and fibrosis. Am J Physiol Gastrointest Liver Physiol. 2016;310:G726-38.

45. Sztalryd C, Bell M, Lu X, Mertz P, Hickenbottom S, Chang BH-J, et al. Functional compensation for adipose differentiation-related protein (ADFP) by Tip47 in an ADFP null embryonic cell line. J Biol Chem.2006;281:34341-8.

46. Dalen KT, Ulven SM, Arntsen BM, Solaas K, Nebb HI. PPARalpha activators and fasting induce the expression of adipose differentiation-related protein in liver. J Lipid Res. 2006;47:931-43.

47. Dalen KT, Schoonjans K, Ulven SM, Weedon-Fekjaer MS, Bentzen TG, Koutnikova H, et al. Adipose tissue expression of the lipid droplet-associating proteins S3-12 and perilipin is controlled by peroxisome proliferator-activated receptor-gamma. Diabetes. 2004;53:1243-52.

48. Libby AE, Bales E, Orlicky DJ, McManaman JL. Perilipin-2 deletion impairs hepatic lipid accumulation by interfering with sterol regulatory element-binding protein (SREBP) activation and altering the hepatic lipidome. J Biol Chem. 2016;291:24231-46.

49. Wiley JL, Burston JJ, Leggett DC, Alekseeva OO, Razdan RK, Mahadevan A, et al. CB1 cannabinoid receptor-mediated modulation of food intake in mice. Br J Pharmacol. 2005;145:293-300.

50. Kaushik S, Cuervo AM. AMPK-dependent phosphorylation of lipid droplet protein PLIN2 triggers its degradation by CMA. Autophagy. 2015;12:432-8.

51. Hardie DG. AMP-activated protein kinase-an energy sensor that regulates all aspects of cell function. Genes Dev. 2011;25:1895-908.

52. Abbud W, Habinowski S, Zhang J-Z, Kendrew J, Elkairi FS, Kemp BE, et al. Stimulation of AMP-activated protein kinase (AMPK) is associated with enhancement of Glut1-mediated glucose transport. Arch Biochem Biophys. 2000;380:347-52.

53. Meireles P, Sales-Dias J, Andrade CM, Mello-Vieira J, MancioSilva L, Simas JP, et al. GLUT1-mediated glucose uptake plays a crucial role during Plasmodium hepatic infection. Cell Microbiol. 2017;19:e12646.

54. Behrooz A, Ismail-Beigi F. Dual control of glut1 glucose transporter gene expression by hypoxia and by inhibition of oxidative phosphorylation. J Biol Chem. 1997;272:5555-62.

55. Loos B, Du Toit A, Hofmeyr J-HS. Defining and measuring autophagosome flux - concept and reality. Autophagy. 2014;10:2087-96.

56. Thakur P, Lamoke F, Chaffin JM, Bartoli M, Lee JR, Duncan MB. Dysplastic hepatocytes develop nuclear inclusions in a mouse model of viral hepatitis. PLoS ONE. 2014;9:e99872.

57. Pugsley HR. Assessing autophagic flux by measuring LC3, p62, and LAMP1 co-localization using multispectral imaging flow cytometry. J Vis Exp. 2017;125:e55637. 